\title{
Characterization of Polysaccharidic Associations for Cosmetic Use: Rheology and Texture Analysis
}

\author{
Giovanni Tafuro ${ }^{1, *}$, Alessia Costantini ${ }^{1}$, Giovanni Baratto ${ }^{2}$, Stefano Francescato ${ }^{2}$, Laura Busata ${ }^{2}$ \\ and Alessandra Semenzato ${ }^{3}$ (D)
}

1 Unired Srl, Via Niccolò Tommaseo 69, 35131 Padova, Italy; alessia.costantini@unired.it

2 Unifarco SpA, Via Cal Longa 62, 32035 Santa Giustina, Italy; gianni.baratto@unifarco.it (G.B.); stefano.francescato@unifarco.it (S.F.); laura.busata@unifarco.it (L.B.)

3 Department of Pharmaceutical and Pharmacological Sciences, University of Padova, Via Marzolo 5, 35131 Padova, Italy; alessandra.semenzato@unipd.it

* Correspondence: giovanni.tafuro@unired.it

Citation: Tafuro, G.; Costantini, A.; Baratto, G.; Francescato, S.; Busata, L.; Semenzato, A. Characterization of Polysaccharidic Associations for Cosmetic Use: Rheology and Texture Analysis. Cosmetics 2021, 8, 62. https://doi.org/10.3390/ cosmetics 8030062

Academic Editor: Piera Di Martino

Received: 29 April 2021

Accepted: 24 June 2021

Published: 26 June 2021

Publisher's Note: MDPI stays neutral with regard to jurisdictional claims in published maps and institutional affiliations.

Copyright: (c) 2021 by the authors. Licensee MDPI, Basel, Switzerland. This article is an open access article distributed under the terms and conditions of the Creative Commons Attribution (CC BY) license (https:// creativecommons.org/licenses/by/ $4.0 /)$.

\begin{abstract}
As public attention on sustainability is increasing, the use of polysaccharides as rheological modifiers in skin-care products is becoming the first choice. Polysaccharide associations can be used to increase the spreading properties of products and to optimize their sensorial profile. Since the choice of natural raw materials for cosmetics is wide, instrumental methodologies are useful for formulators to easily characterize the materials and to create mixtures with specific applicative properties. In this work, we performed rheological and texture analyses on samples formulated with binary and ternary associations of polysaccharides to investigate their structural and mechanical features as a function of the concentration ratios. The rheological measurements were conducted under continuous and oscillatory flow conditions using a rotational rheometer. An immersion/deimmersion test conducted with a texture analyzer allowed us to measure some textural parameters. Sclerotium gum and iota-carrageenan imparted high viscosity, elasticity, and firmness in the system; carob gum and pectin influenced the viscoelastic properties and determined high adhesiveness and cohesiveness. The results indicated that these natural polymers combined in appropriate ratios can provide a wide range of different textures and that the use of these two complementary techniques represents a valid pre-screening tool for the formulation of green products.
\end{abstract}

Keywords: polysaccharides; rheology; texture; cosmetics; eco-design

\section{Introduction}

The use of natural polymers in cosmetics is growing, especially in the last few years, driven by the general interest in sustainability and environmental issues [1]. To meet the growing demand for raw materials that can replace the traditional non-biodegradable synthetic polymers, the market has increased the choice of polysaccharides for cosmetic use. Nature offers a wide variety of polysaccharides with different chemical structures and different properties. The multifunctionality of polysaccharides, due to their chemical structure, which has several hydroxyl groups that are able to bind water molecules, allows their use in different formulations as moisturizing agents, thickeners, stabilizers, and texturizers [2]. However, matching the performance of synthetic polymers using polysaccharides can be quite challenging, since synthetic polymers are artificially created to have a specific role in a formulation. Manufacturers have to choose the natural raw materials that best fit the formulation design, without losing the sensorial characteristics and the functional-stability aspects imparted by synthetic polymers, opting for binary or multiple polysaccharide mixtures whose properties are unique and different from those of the single materials.

Even if the physical-mechanical properties of pure polysaccharides are well known, since many scientific works have deeply investigated them [3], manufacturers often lack 
technical information about the raw materials' molecular weights, degree of substitution, and chemical features. The information contained in the natural raw materials' technical data sheets provided by the supplier companies is purely indicative of their use in a formulation, and the interactions between different polysaccharides are difficult to predict. For these reasons, formulators, relying on their experience and creativity, have been using the traditional trial and error formulation approach to associate different polysaccharides to achieve the functional and sensorial objectives. The tactile and sensorial profile is indeed the main driver of the purchase behavior and therefore, it must be coherent with the consumers' expectations [4]. The combination of functional and sensorial aspects leads to what is known as the perceived effectiveness of a cosmetic product, which derives from the contribution of each different ingredient on the overall quality of the formula.

Cosmetic industries are seeking for more reproducible, simple, and fast instrumental methods to support every phase of the eco-design process. This involves characterizing the applicative properties of each natural raw material, evaluating the compatibility and the advantages of their use in associations in adequate ratios and concentrations that allow a synergistic action, and comparing the results with those of the benchmarks in the market. Rheology and texture analysis have proven to be valid tools for the pre-screening process of raw materials to predict their contribution to the final formula $[5,6]$.

Rheological measurements, performed both in continuous and oscillatory flow conditions, are used for the characterization of semi-solid materials, to evaluate the spreading properties of the products, and to study their inner structure and stability $[7,8]$. Texture analysis, commonly used in the food industry [9], has been introduced in the cosmetic field to study the mechanical properties of products, which are linked to their sensory characteristics $[10,11]$.

In this work, rheological and texture analyses were conducted on a set of samples formulated by dispersing polysaccharidic associations in water and evaluating the influence of their concentrations on the physical-mechanical properties of the systems. The raw materials used in this study have been deeply characterized in our previous work [12]. We selected materials for which the rheological and texture characteristics make them suitable for the formulation design of a mucoadhesive gel. A product that is intended to be applied on the oral mucosa for protection or for in situ release of active molecules contains ingredients that ensure adhesive and cohesive properties and thus to adhere to the application site, without flaking or being removed by facial mechanical movements, swallowing, or salivation. Moreover, these ingredients must provide adequate viscosity and firmness so that the product is not too thick to result in difficult extrusion from the container $[13,14]$. These properties are usually conferred by cross-linked polyacrylic polymers or PVP, but polysaccharides have also demonstrated their suitability [15]. Sclerotium gum and iota-carrageenan were chosen for their thickening properties, since they form structured systems with weak gel rheological properties. Sclerotium gum is a microbial-derived non-ionic polysaccharide characterized by a linear chain of $(1,3)-\beta$-D-glucose with a single $(1,6)-\beta$-D-glucose every third unit of the main chain [16]. Carrageenan, extracted from Chondrus crispus seaweed, is composed of alternating (1,3)- $\beta$-D-galactose and $(1,4)-3,6$ anhydro- $\alpha$-D-galactose monomers, with acidic sulfate groups; it forms soft and elastic gels in the presence of bivalent ions [17]. Carob gum (Ceratonia siliqua gum) was chosen for its viscoelastic and bioadhesive properties [18]. It is a plant-derived galactomannan consisting of a $(1,4)-\beta$-D-mannose backbone with side groups of $\alpha$-D-galactose linked at Position 6 . The degree of substitution (i.e., the number of side units per unit length of the main chain) is 1:4 between galactose and mannose units [19]. Pectins were introduced to improve the spreadability of the systems. They are characterized by linear methyl-esterified $(1,4)-\alpha$-D-galacturonic acidic sequences, and the degree of esterification strictly depends on the natural source [20].

The aim of this work was thus to characterize the rheological and texture properties of different polysaccharidic dispersions, finding the associations of polysaccharides mixed at adequate ratios that conveniently modulated the structure and the texture properties of 
the systems. A combination, which imparted high viscosity, spreadability, and adhesive properties, was selected and the results have been compared with those obtained from a benchmark in the market for mucosal application.

\section{Materials and Methods}

\subsection{Materials}

Four natural raw materials for cosmetic use were selected. To simplify comprehension of the results, these polymers are identified with a letter of the alphabet. Actigum CS 11 QD (A) supplied by Cargill (Wayzata, MN, USA) is a Sclerotium gum-based powder produced by an aerobic fermentation process; it is a quickly soluble stabilizing and texturizing agent. Genuvisco CG-131 (G) is a powder of iota-carrageenan supplied by CP Kelco (Atlanta, GA, USA), a sulfated polysaccharide extracted from certain species of red seaweed, which form elastic and cohesive gels in the presence of bivalent ions. Vari Carruba (C) is a Ceratonia siliqua gum supplied by Variati (Concorezzo, MB, Italy) that is COSMOS certified; it is a natural hydrocolloid extracted from carob tree seeds with texturizing and stabilizing properties. Vari Pectin (P), supplied by Variati (Concorezzo, MB, Italy), is a spreadable beige powder consisting of a blend of standardized pectins obtained from citrus peel, with a methylation degree of $46-50 \%$. The physico-mechanical properties of the polysaccaridic associations were compared with those of Alovex gel (reference product), a product for oral aphthous ulcer treatment, purchased from a pharmacy.

\subsection{Methods}

The samples were prepared by dispersing the powder of each raw material, alone or in combination with the others, in distilled water at $50-55^{\circ} \mathrm{C}$ under continuous stirring at $700 \mathrm{rpm}$ using a DLS Digital Overhead Stirrer (VELP Scientifica s.r.l., Usmate Velate, MB, Italy) until homogeneity.

The samples studied in this work, including the concentrations used, are listed in Table S1 (see Supplementary Materials). G needed the addition of a divalent salt (G: $\mathrm{MgSO}_{4}$ ratio, 2:1) to jellify. After the polymers' complete dispersion, the $\mathrm{pH}$ of the samples needed to be adjusted with citric acid to a value of 4-5, suitable for topical application or on the oral mucosa and to protect from microbial contamination. Since pectin dispersions have low $\mathrm{pH}$ values, the $\mathrm{pH}$ of the samples containing $\mathrm{P}$ were adjusted with a solution of $\mathrm{NaOH}(10 \% w / w)$. Some pictures of the systems obtained are shown in Figure S1. The samples were stored at $23{ }^{\circ} \mathrm{C}$ for at least 4 days before carrying out the rheological and the texture analyses.

The rheological analyses were performed under continuous and oscillatory flow conditions using a Rheometer Physica MCR-101 from Anton Paar (Anton Paar GmBH, Graz, Austria), equipped with a CP50-1 sensor (cone-plate geometry) with a fixed gap $(0.098 \mathrm{~mm})$. All the measurements were conducted at a controlled temperature of $23^{\circ} \mathrm{C} \pm 0.05$ and taken in triplicate to ensure the reproducibility of the data (Figure S2). The dispersions flow properties were measured under continuous flow conditions by a controlled shear rate test (CSR), by recording the viscosity values $(\eta)$ at an increasing shear rate, ranging from 0.001 to $1000 \mathrm{~s}^{-1}$. The viscosity at rest $\left(\eta_{0}\right)$ was calculated by fitting the flow curves of the different samples with the Carreau-Yasuda model that describes the shear-thinning behavior of materials [21]. The viscoelastic properties were studied under oscillatory flow conditions. The linear viscoelastic region (LVR) of each sample was identified at a fixed frequency of $1 \mathrm{~Hz}$ and an increasing strain $(\gamma)$ from $0.01 \%$ to $1000 \%$. The mechanical spectra of the samples, i.e., the trend of the storage $\left(G^{\prime}\right)$ and loss $\left(G^{\prime \prime}\right)$ moduli, were studied at a fixed strain taken from the LVR and varying the oscillation frequency from $10 \mathrm{~Hz}$ to $0.01 \mathrm{~Hz}$.

An immersion/de-immersion test was conducted at room temperature using a TMS-Pro Texture Analyzer, from Food Technology Corporation (Sterling, VA, USA), equipped with a load cell of $10 \mathrm{~N}$ and a spherical nylon probe ( $2 \mathrm{~cm}$ diameter). After loading the samples into $50 \mathrm{~mL}$ containers (5.3 cm diameter), the probe penetrated each sample to a depth of $10 \mathrm{~mm}$ 
at a rate of $1.3 \mathrm{~mm} \mathrm{~s}^{-1}$ and then returned to its start position. The test was repeated 3 times. Texture Lab Pro was used to collect and display the data. From the curve plotted as load (N) vs cumulative displacement $(\mathrm{mm})$, illustrated in Figure S3, the following parameters were obtained: firmness, consistency, cohesiveness, adhesiveness, and stringiness. Firmness is the positive peak and refers to the maximum value of force needed to obtain a deformation and is expressed in Newtons $(\mathrm{N})$. Consistency is the area under the positive curve $(\mathrm{N} \cdot \mathrm{mm})$ and represents the total work of the sample against the deformation. Cohesiveness is the negative peak $(\mathrm{N})$ recorded during the movement of the probe upwards and is related to the intramolecular forces of the sample. Adhesiveness is the area under the negative portion of the curve $(\mathrm{N} \cdot \mathrm{mm})$ and is defined as the work needed to overcome the attractive forces between the surface of the sample and the surface of another material with which it comes in contact. Stringiness is the distance $(\mathrm{mm})$ to which the product hangs on the probe when the probe is withdrawn [10].

\section{Results and Discussion}

\subsection{Rheology}

\subsubsection{Characterization of Carrageenan (G) and Carob Gum (C) Associations}

The naturally derived raw materials used in this work have been characterized using rheological and texture analyses in our previous study [12]. Carob gum (Ceratonia siliqua gum) dispersed in water formed viscoelastic and stringy solutions, with high spreadability and good pick-up properties. The applicative properties of this material make it suitable for associations with other polysaccharides that can strengthen the structure and increase the viscosity of the system, like carrageenans, which, in water, form elastic gels [22]. The rheological behavior of monodisperse systems made with iota-carrageenan (G) and Ceratonia siliqua gum (C) used at $1.5 \% w / w$ have been compared with that of the binary association at the same total polymer amount (G:C =1:3). A controlled shear rate test was performed to study the viscosity trend as a function of the shear rate applied (Figure 1). The samples were characterized by their shear-thinning behavior, as viscosity progressively decreased under shear application [3]. At lower shear rates, the viscosity remained almost constant, in the so-called Newtonian plateau region; as the shear rate increased, a reduction in the viscosity was observed, as the polymer molecules were aligned toward the flow direction. $G$ dispersed alone formed gels with high viscosity ( $\left.\eta_{0} 55906.06 \mathrm{~Pa} \cdot \mathrm{s}\right)$, whereas $C$ reached lower values of viscosity ( $\left.\eta_{0} 21.57 \mathrm{~Pa} \cdot \mathrm{s}\right)$. The association of $\mathrm{C}$ and $\mathrm{G}$ showed a viscosity at rest over two magnitude orders higher than C alone ( $\eta_{0}$ G-C 1-3 $\left.9534.75 \mathrm{~Pa} \cdot \mathrm{s}\right)$, and a more marked shear-thinning behavior since a rapid decrease in viscosity at increasing shear rate was observed.

The viscoelastic properties as a function of the frequency were investigated. The frequency sweep test was conducted at a fixed oscillation amplitude within the linear viscoelastic range (Figure 2). The $C$ dispersion showed a typical viscoelastic behavior, with both the storage $\left(G^{\prime}\right)$ and the loss $\left(G^{\prime \prime}\right)$ moduli being significantly dependent on the frequency with a crossover point: when high frequencies were applied, the $G^{\prime}$ modulus was higher than the $G^{\prime \prime}$ modulus, which became predominant at lower frequencies [23]. G dispersed alone showed a weak gel rheological pattern, with $G^{\prime}$ being larger than $G^{\prime \prime}$ throughout the whole frequency range investigated (Figure 2a) [24]. This behavior indicated that the elastic components of the system dominated over the viscous components, and that the system's structure was held by physical bonds between the macromolecules. When the two polymers $C$ and $G$ were combined, a weak gel trend of the moduli was observed, with a strong dependence of both moduli on the frequency applied (Figure $2 b$ ).

Figure 3 shows the damping factor $(\tan \delta)$ values as a function of the frequency applied. Tan $\delta$ represents the ratio between the viscous modulus $G^{\prime \prime}$ and the elastic modulus $G^{\prime}$, and allows us to define the weight of the elastic component. $C$ showed the highest values of $\tan \delta$, having a predominant viscous component, and this indicated a greater dissipative capacity than the other materials. $G$ was characterized by the lowest values of $\tan \delta$ and a 
more elastic behavior. As expected, by mixing the two polysaccharides, a modulation of the viscoelastic properties can be achieved.

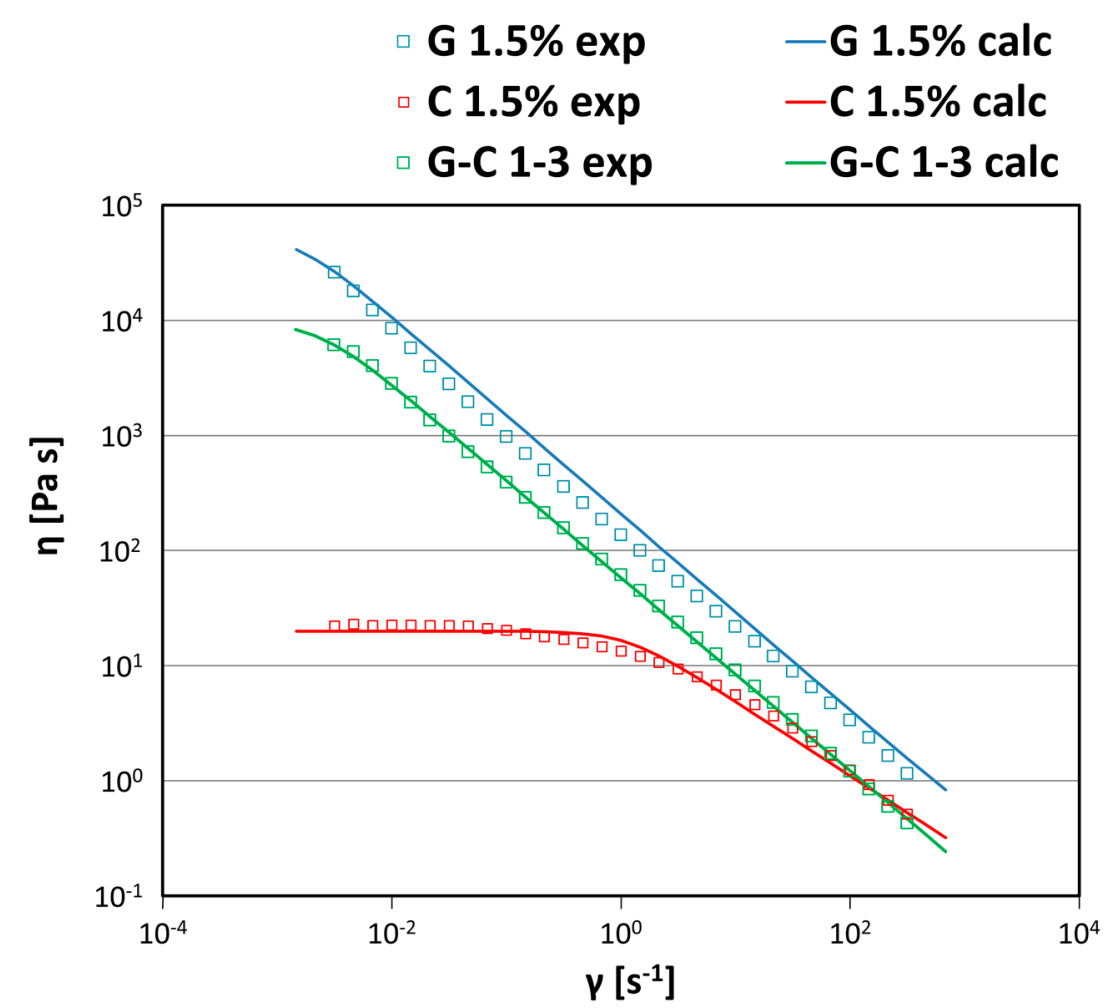

Figure 1. Viscosity curves as a function of the shear rate for the samples prepared with $G, C$, and the G-C association (1:3) at the same total polymer amount $(1.5 \% w / w)$. Flow curves (exp) were fitted with the Carreau-Yasuda model (calc).

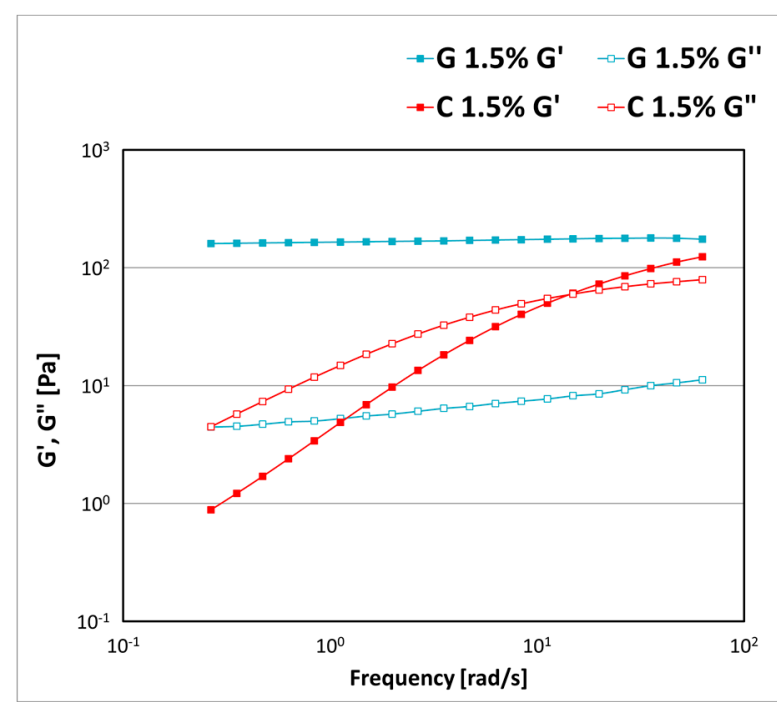

(a)

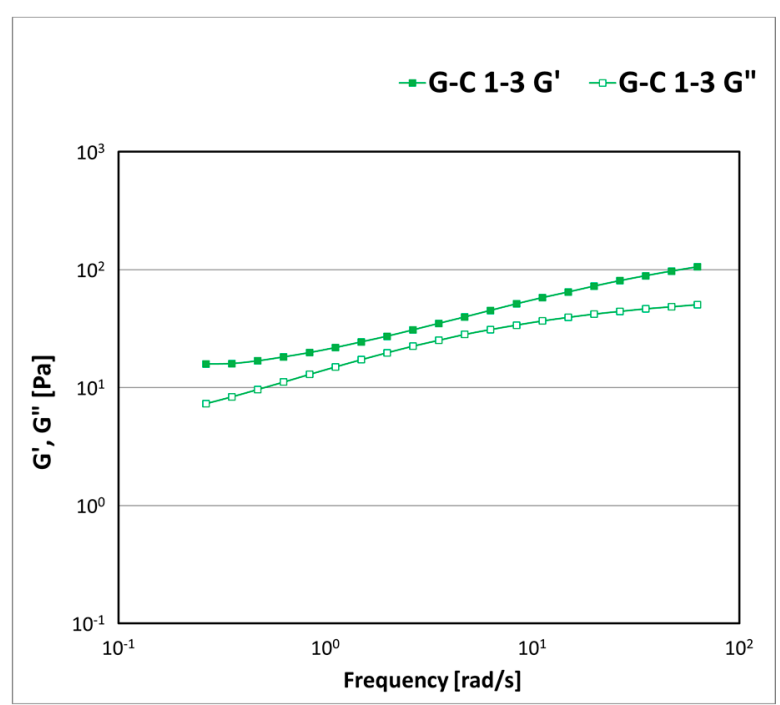

(b)

Figure 2. Storage $\left(G^{\prime}\right)$ and loss $\left(G^{\prime \prime}\right)$ moduli trends as a function of the frequency for the samples prepared with $G$ and $\mathrm{C}(\mathbf{a})$ and the G-C association (1:3) (b) at the same total polymer amount (1.5\% w/w).

The values of $\mathrm{G}^{\prime}$ and $\mathrm{G}^{\prime \prime}$ (taken at a frequency of $1 \mathrm{~Hz}$ ) of the $\mathrm{G}-\mathrm{C}$ associations used at a ratio of $1: 3$ and increasing polymer concentrations are reported in Figure 4. Lower concentrations $(0.75 \%)$ produced the formation of liquid-like systems with a higher loss modulus $\left(\mathrm{G}^{\prime \prime}\right)$. Higher concentrations were needed to have gel-like systems with 
greater elastic properties. Over $1 \%$ of the total polymer amount, $G^{\prime}$ dominated over $G^{\prime \prime}$, and both moduli increased by increasing the polymer concentrations.

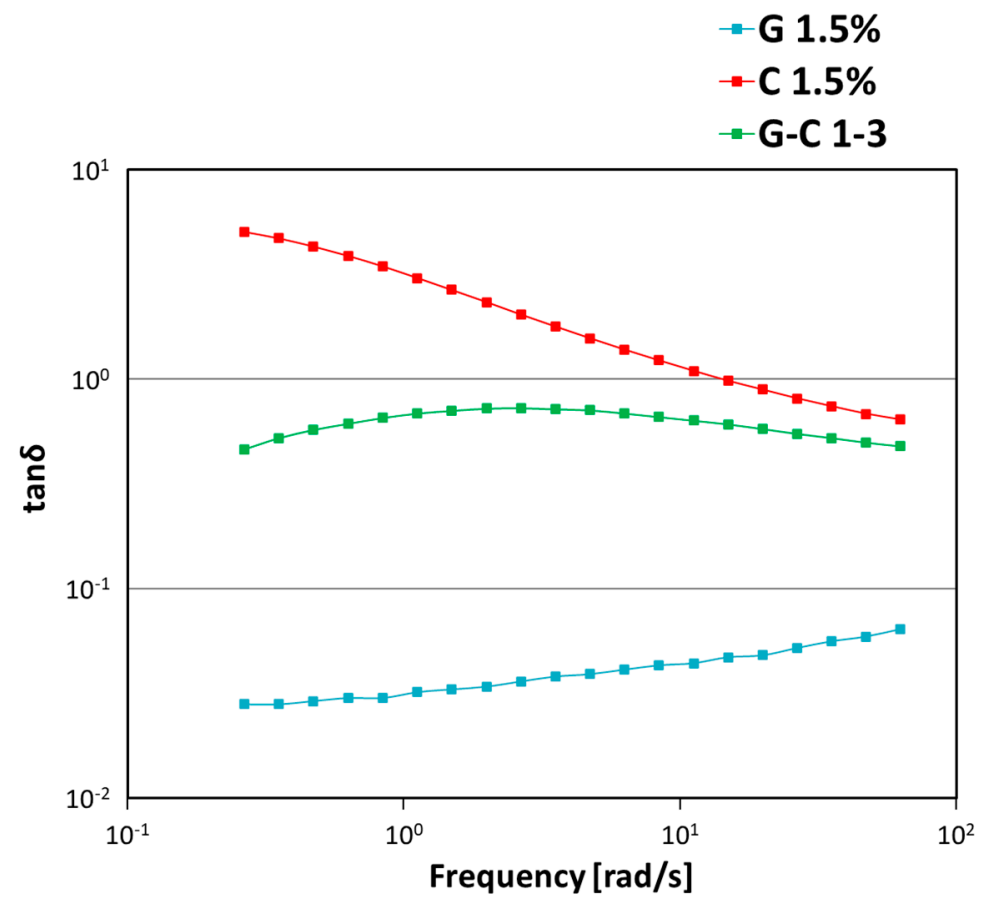

Figure 3. Damping factor $\tan \delta$ trends as a function of the frequency for the samples prepared with G, $\mathrm{C}$, and the $\mathrm{G}-\mathrm{C}$ association (ratio $1: 3$ ) at $1.5 \%$ w/w of the total polysaccharide amount.

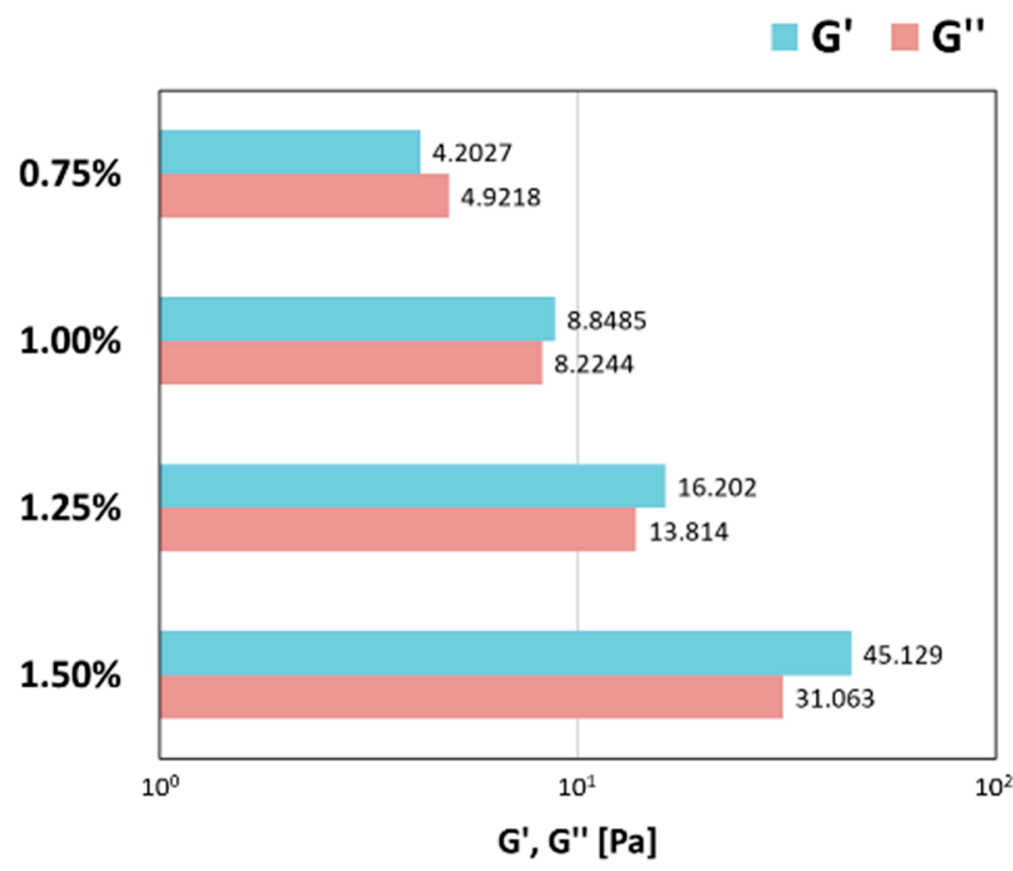

Figure 4. Values of the storage $\left(\mathrm{G}^{\prime}\right)$ and loss $\left(\mathrm{G}^{\prime \prime}\right)$ moduli measured at a fixed oscillation frequency of $1 \mathrm{~Hz}$ for the samples prepared with G-C associations (ratio of 1:3) as a function of the total polymer amount $(0.75 \%, 1 \%, 1.25 \%$, and $1.5 \% w / w)$.

\subsubsection{Characterization of Sclerotium Gum (A) and Carob Gum (C) Associations}

Figure 5 shows the flow curves of the dispersed systems prepared using Sclerotium gum (A) and Ceratonia siliqua gum (C). A dispersion at $1.5 \%$ w/w showed a shear-thinning behavior with higher values of viscosity $\left(\eta_{0} 5334.51 \mathrm{~Pa} \cdot \mathrm{s}\right)$ than $\mathrm{C}$ dispersions at the same 
concentration. The association between $\mathrm{A}$ and $\mathrm{C}$ at a ratio of 3:2 showed intermediate values of viscosity between the monodisperse systems $A$ and $C\left(\eta_{0} 316.54 \mathrm{~Pa} \cdot \mathrm{s}\right)$.



Figure 5. Viscosity curves as a function of the shear rate for the samples prepared with A, C, and the A-C association (3:2) at the same total polymer amount $(1.5 \% w / w)$. Flow curves (exp) were fitted with the Carreau-Yasuda model (calc).

In the mechanical spectra reported in Figure 6a, A showed a weak gel rheological pattern, with $G^{\prime}$ being higher than $G^{\prime \prime}$ in the entire frequency range investigated [25], while $C$ had a viscoelastic profile. The $\mathrm{A}-\mathrm{C}$ dispersions showed a weak gel pattern, with moduli values lower that those measured for the A dispersion and a stronger dependence on the frequency applied (Figure $6 b$ ).

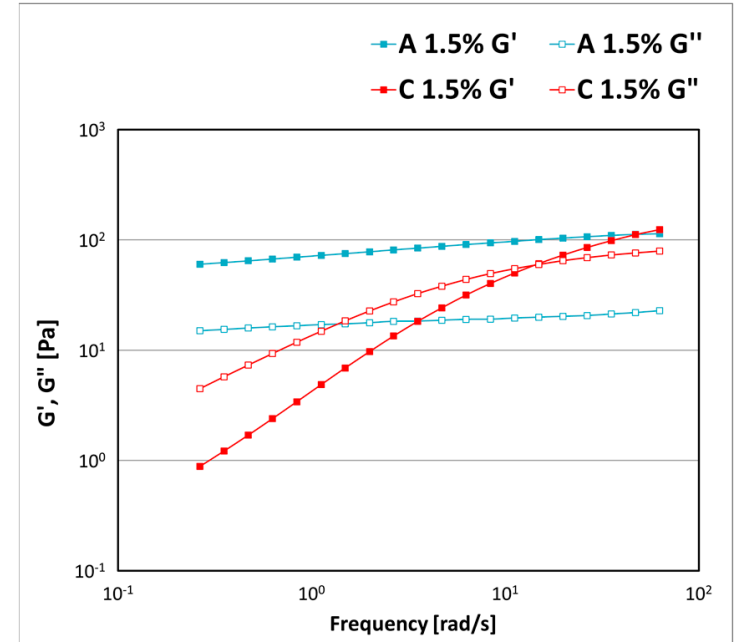

(a)

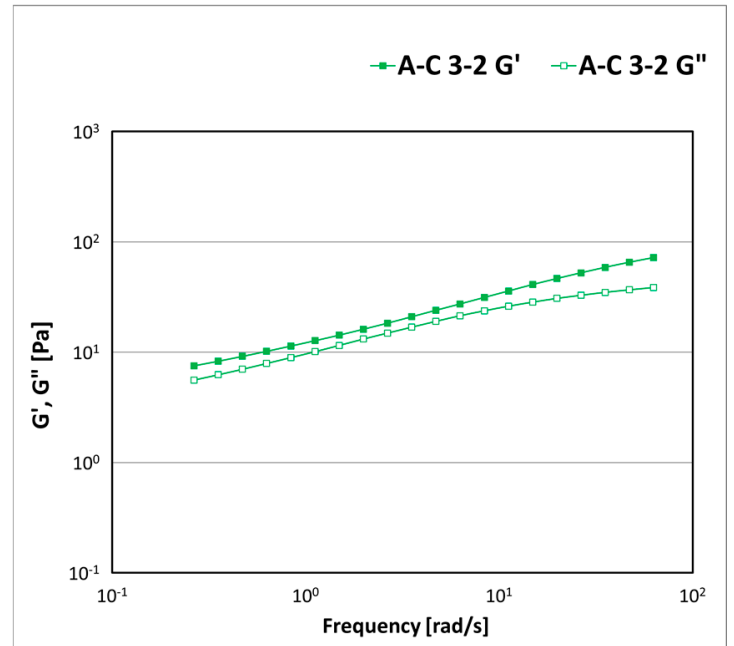

(b)

Figure 6. Storage $\left(\mathrm{G}^{\prime}\right)$ and loss $\left(\mathrm{G}^{\prime \prime}\right)$ moduli trends as a function of the frequency for the samples prepared with A and $\mathrm{C}(\mathbf{a})$ and the A-C association (3:2) (b) at the same total polymer amount (1.5\% w/w).

A was characterized by the lowest values of $\tan \delta$ and more elastic behavior. The association of polymers $A$ and $C$ resulted in a modulation of the viscoelastic properties (Figure 7). 


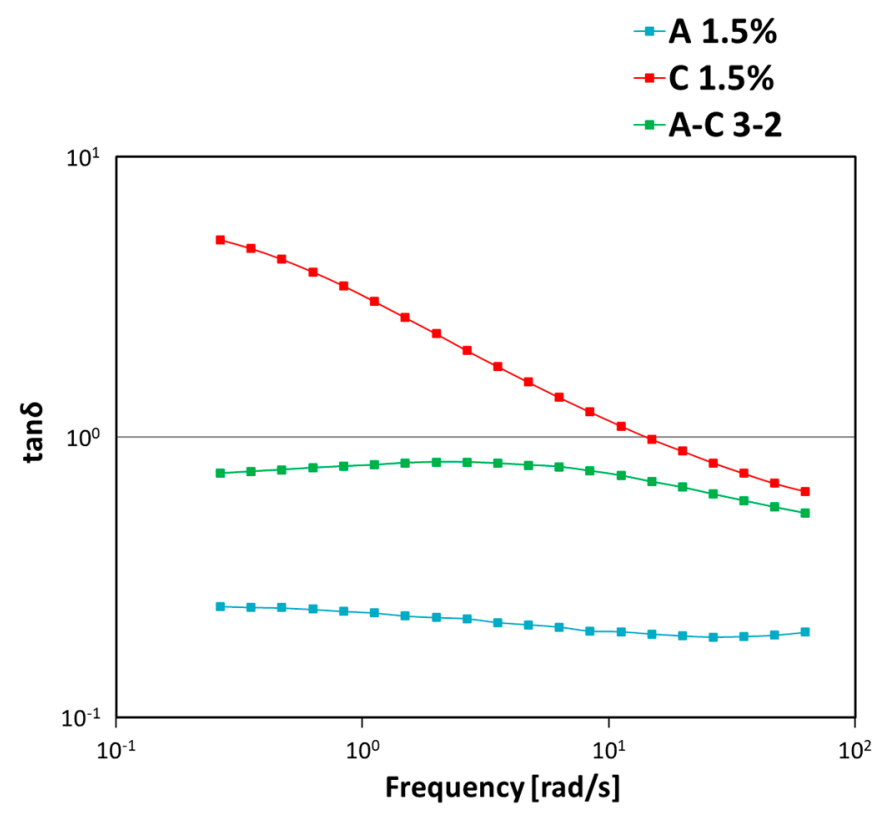

Figure 7. Damping factor tan $\delta$ trends as a function of the frequency for the samples prepared with A, $\mathrm{C}$, and the $\mathrm{A}-\mathrm{C}$ association (ratio $3: 2$ ) at $1.5 \% w / w$ of the total polysaccharide amount.

The modulus values of the systems prepared with $A$ and $C$ in association increased with increasing polymer concentrations, since more polymer-polymer and polymersolvent interactions were formed (Figure 8).

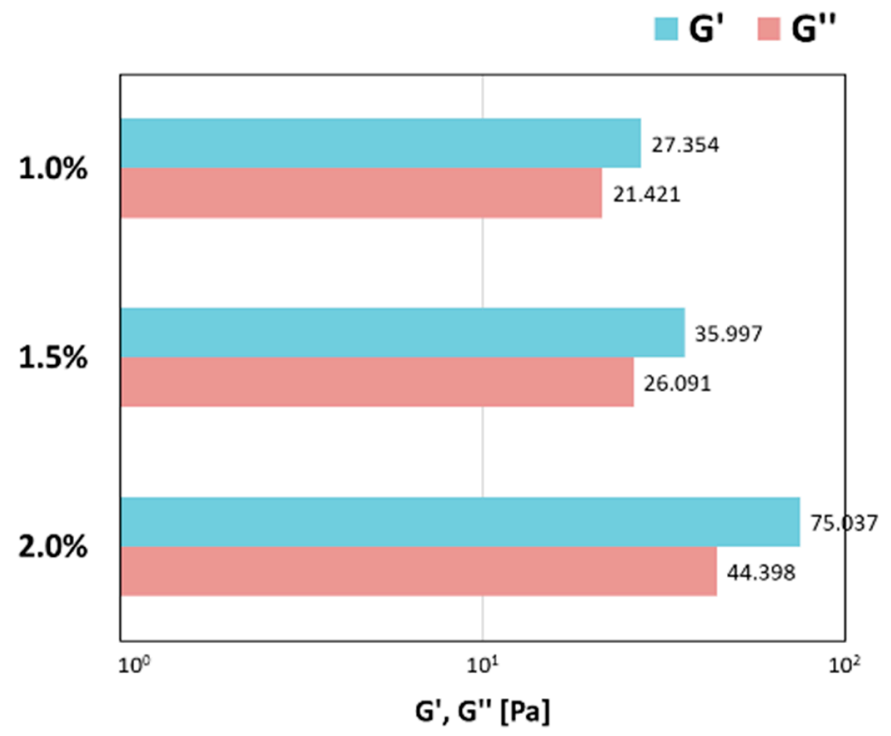

Figure 8. Values of the storage $\left(\mathrm{G}^{\prime}\right)$ and loss $\left(\mathrm{G}^{\prime \prime}\right)$ moduli measured at a fixed oscillation frequency of $1 \mathrm{~Hz}$ for the samples prepared with A-C associations (ratio of 3:2) as a function of the total polymer amount $(1 \%, 1.5 \%$, and $2 \% w / w)$.

\subsubsection{Characterization of Ternary Systems: Sclerotium Gum (A), Carob Gum (C), and Pectin $(\mathrm{P})$}

To increase the system's viscous properties, which are related to the ease of application on the skin and the spreading properties, a pectin-based raw material $(\mathrm{P})$ was introduced and ternary systems were formulated. P (i.e., pectin) consists of a mixture of pectins with different methylation degrees which give a semi-flexible structure to the polymer, guaranteeing adhesive characteristics. As reported in the technical data sheet provided by the supplier company, this raw material, being a particular association of different pectins, 
forms a three-dimensional network in water. $\mathrm{P}$ at $4 \% w / w$ consisted of a system which exhibited liquid-viscous properties with $G^{\prime \prime}$ being greater that $G^{\prime}$ over the entire frequency range examined (Figure 9).

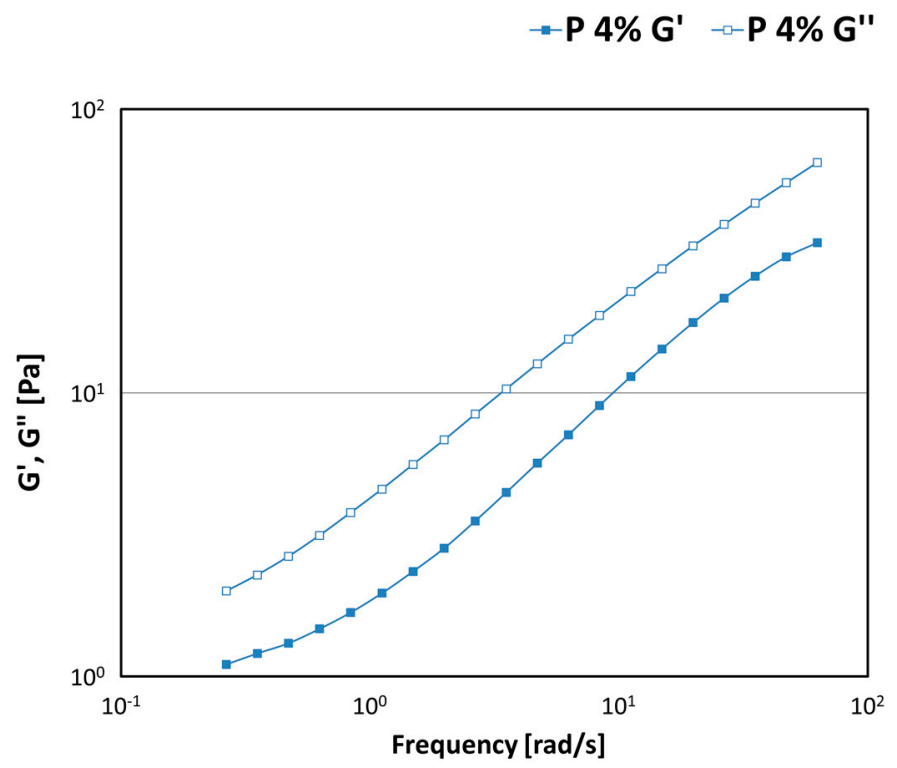

Figure 9. Storage $\left(G^{\prime}\right)$ and loss $\left(G^{\prime \prime}\right)$ moduli trend as a function of the frequency for the sample prepared with $\mathrm{P}$ at $4 \% w / w$.

The controlled shear rate test performed on the water dispersions prepared with polymers A, C, and P in association highlighted the samples' pseudoplastic behavior, as the viscosity decreased at increasing shear rate values (Figure 10a) [26]. The zero-shear viscosity $\left(\eta_{0}\right)$ values were calculated using the Carreau-Yasuda model. When $1 \% w / w$ of $\mathrm{P}$ was added to the A-C mixture, a decrease in viscosity was observed, whereas $\mathrm{P}$ at $2 \% w / w$ determined a sharp increase in the viscosity of the system (Figure 10b).

The mechanical spectra of the samples prepared with ternary associations of A, C, and increasing concentrations of $\mathrm{P}(0 \%, 1 \%$, and $2 \% w / w)$, are shown in Figure 11 . The data measured by the frequency sweep analysis confirmed the results obtained under continuous flow conditions, as a decrease in both moduli was observed when $1 \% w / w$ of $\mathrm{P}$ was added to the A-C mixture, whereas $\mathrm{P}$ at $2 \% w / w$ produced an increase in the viscoelastic properties of the system. These data suggest that, if present at $1 \% w / w, \mathrm{P}$ subtracts water from the other two polymers and does not contribute to the structure of the network, while at the concentration of $2 \% w / w$, it contributes to the formation of the network, with a synergistic effect with the other two polymers.

\subsection{Texture Analysis}

\subsubsection{Characterization of Carrageenan $(\mathrm{G})$ and Carob Gum (C) Associations}

An immersion/de-immersion test was conducted on the monodisperse samples prepared with $G$ and $C$, and on the association between them at a ratio of 1:3 (Figure 12). $G$ showed high values of firmness (maximum of the positive curve) and consistency (area under the positive curve), with extremely low adhesiveness (area under the negative curve) and stringiness (tailing) [27]. It is a bouncy gel with low pick-up properties. $C$ formed a fluid system with low values of firmness and consistency and high stringiness, thus indicating easy spreadability. The association of these polysaccharides allowed modulation of the textural properties, showing intermediate values of firmness, adhesiveness, and stringiness between those obtained with the single raw materials used at the same concentration $(1.5 \% w / w)$. 


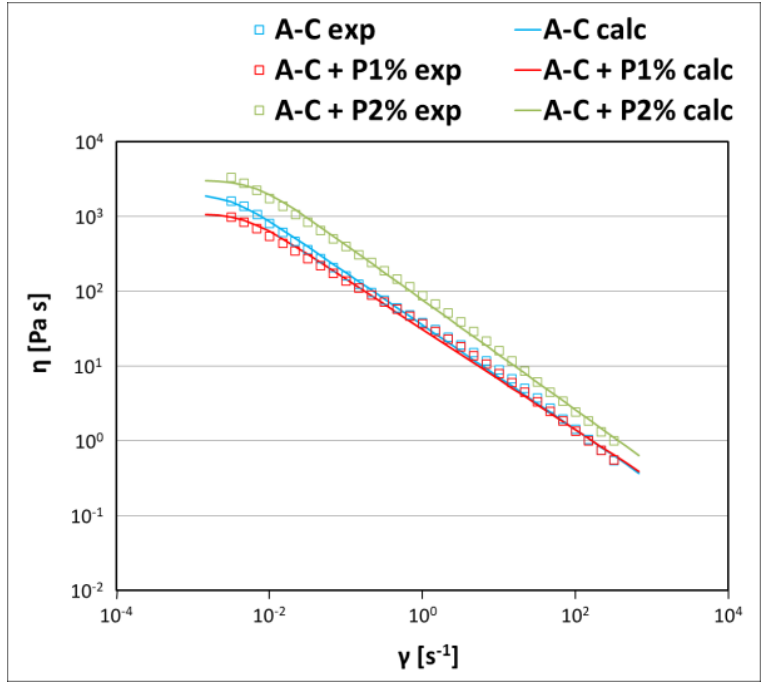

(a)

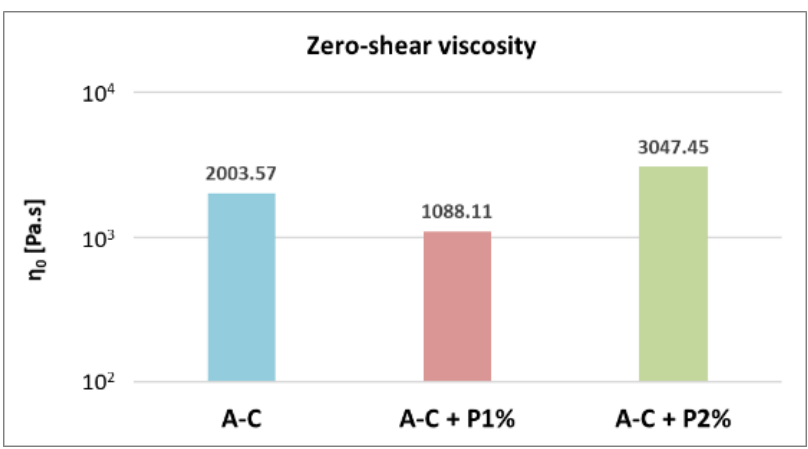

(b)

Figure 10. Viscosity trend as a function of the shear rate (a) with flow curves (exp) fitted with the Carreau-Yasuda model (calc), and zero shear viscosity $\left(\eta_{0}\right)$ values $(\mathbf{b})$, for the samples prepared with ternary associations of $A(1.25 \% w / w)$, $\mathrm{C}(1 \% w / w)$, and increasing concentrations of $\mathrm{P}(0 \%, 1 \%$, and $2 \% w / w)$.

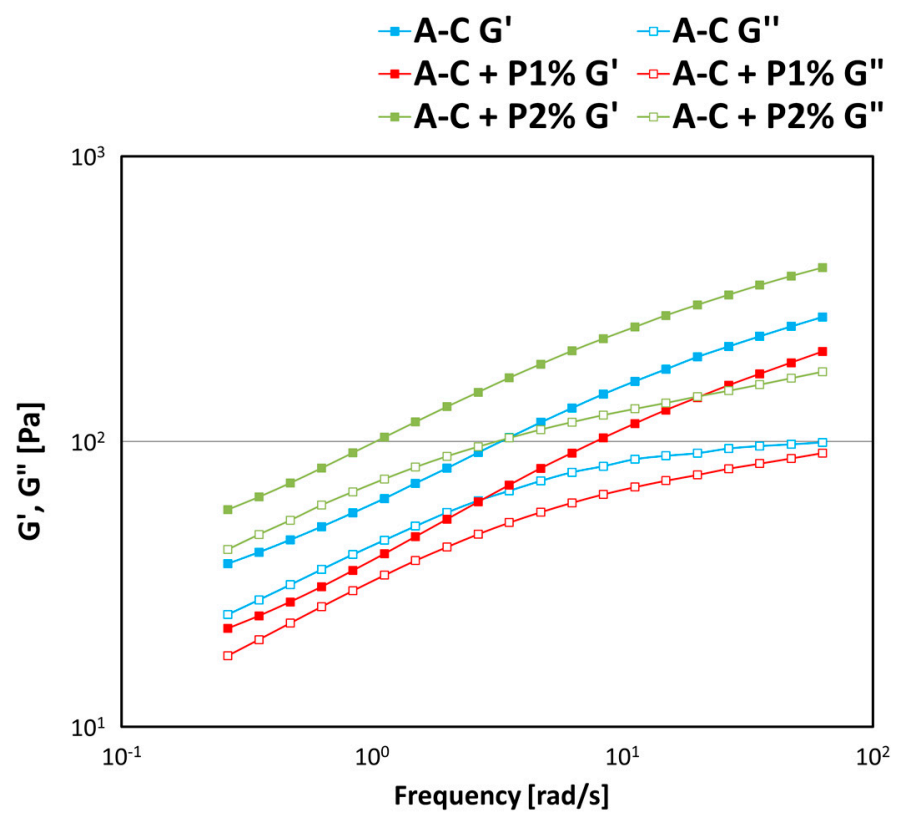

Figure 11. Storage $\left(G^{\prime}\right)$ and loss $\left(G^{\prime \prime}\right)$ moduli trends as a function of the frequency for the samples prepared with ternary associations of A $(1.25 \% w / w), \mathrm{C}(1 \% w / w)$, and increasing concentrations of $\mathrm{P}(0 \%, 1 \%$, and $2 \% w / w)$.

The association between $C$ and $G$ strongly modulated the texture properties of the gels. The curves obtained by the texture analysis of the samples prepared using $\mathrm{G}-\mathrm{C}$ associations at different ratios (1:2 and 1:3) are reported in Figure 13. With an increase in the total polysaccharide amount (from $0.75 \%$ to $1.5 \% w / w$ ), a significative increase in the parameters of firmness and consistency was observed, since the force needed to deform the gel became higher as more polymer-solvent interactions were formed. With a ratio of 1:2 between $G$ and $C$, higher textural values were achieved (Figure 13a). Increasing the contribution of $C$, using a ratio of 1:3 between $G$ and C, decreased firmness and consistency (Figure 13b), thus determining higher spreadability and ease of application on the skin, since the lower the force necessary to reach a given deformation, the higher the spreadability. The polymer 
concentration also affected the last part of the curve and the shape of the negative peak, which is related to the sample cohesive properties. Smooth and monotonous curves were observed for polymer concentrations of $0.75 \%$ and $1 \% w / w$. At higher concentrations such as $1.5 \% w / w$, especially using a G-C ratio of $1: 2$, the curves became irregular, and the presence of unresolved shoulders could be seen. This suggested that the withdrawal of the probe from the sample consisted of several steps, and this could be related to the inhomogeneous micro-gel structure. In practical evaluations, as reported in the literature, such a material is referred to as being "choppy", which is considered to be detrimental to the product's texture, as it makes uniform spreading on the surface of the skin difficult [10]. For these reasons, the use of $\mathrm{G}-\mathrm{C}$ mixtures at concentrations above $1 \% w / w$ is not recommended.

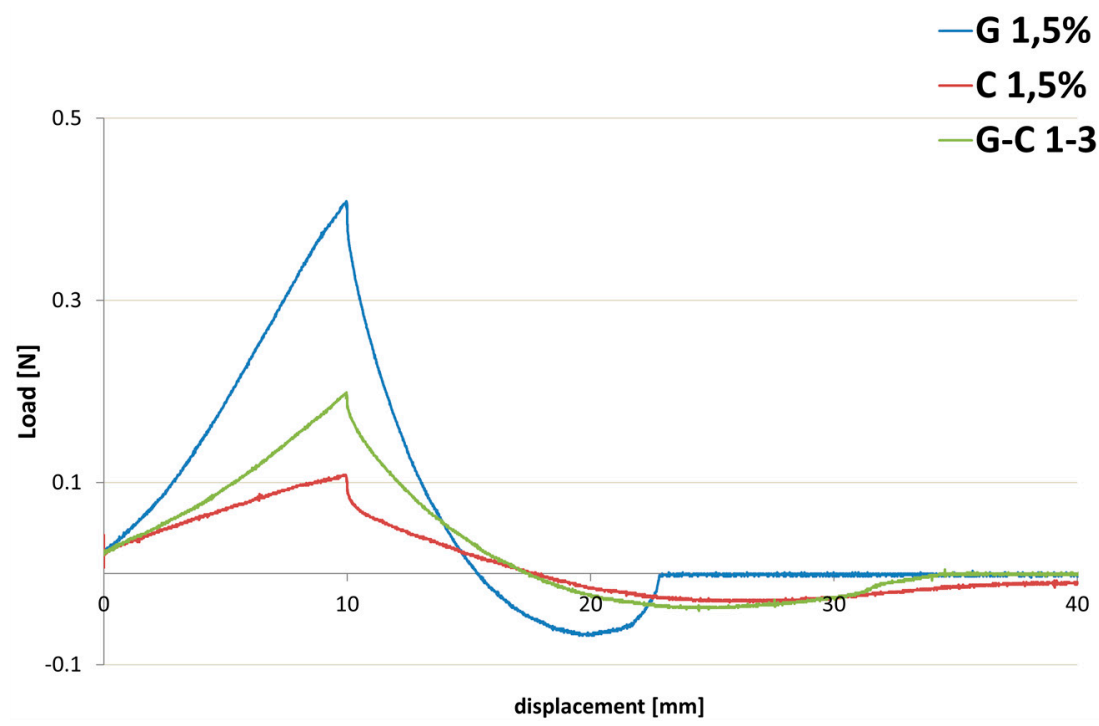

Figure 12. Texture curves obtained by an immersion/de-immersion test performed on the samples prepared with G, C, and the G-C association (1:3) at the same total polymer amounts $(1.5 \% \mathrm{w} / \mathrm{w})$.

\subsubsection{Characterization of Sclerotium Gum (A) and Carob Gum (C) Associations}

The A dispersion at $1.5 \% w / w$ was characterized by high firmness and consistency, with medium to low adhesive properties. As it has been seen for xanthan gum in previous studies [28,29], we investigated if the association of this polysaccharide with $C$ allowed modulation of the textural properties (Figure 14). The A-C association at a ratio of $3: 2$ and $1.5 \%$ of total polysaccharide showed intermediate values of firmness, adhesiveness, and stringiness between those obtained with the single raw materials used at the same concentration.

As expected, with an increase in the total polysaccharide concentration at a fixed A-C ratio of 3:2, the textural parameters increased in terms of firmness, consistency, cohesiveness, and adhesiveness, maintaining high stringiness (Figure 15).

Figure 16 shows how the texture parameters of adhesiveness and stringiness can be modulated using different ratios of $\mathrm{A}-\mathrm{C}$ associations at the same total polymer amount $(1.5 \% w / w)$. In particular, the A-C ratio of 3:2 allowed higher values of adhesiveness and stringiness, since higher forces were needed to detach the sample from the probe and a longer strand was formed during its withdrawal.

\subsubsection{Characterization of Ternary Systems: Sclerotium Gum (A), Carob Gum (C), and Pectin $(\mathrm{P})$}

The texture curves of the samples formulated with ternary associations of $\mathrm{A}(1.25 \% w / w)$, $\mathrm{C}(1 \% w / w)$, and increasing concentrations of $\mathrm{P}(0 \%, 1 \%$, and $2 \% w / w)$ are shown in Figure 17 . In line with the data obtained from the rheological analyses (Figure 11), the addition of $P$ influenced the shape of the first part of the curve, as it caused a rearrangement of the polymer chains and a change in the microgel structure, forming a more fluid system with less firmness and consistency than the sample without P. However, when P was inserted 
at higher concentrations $(2 \% w / w)$, the system became more structured and stiffer, and an increase in the texture parameters occurred, including adhesiveness and cohesiveness.

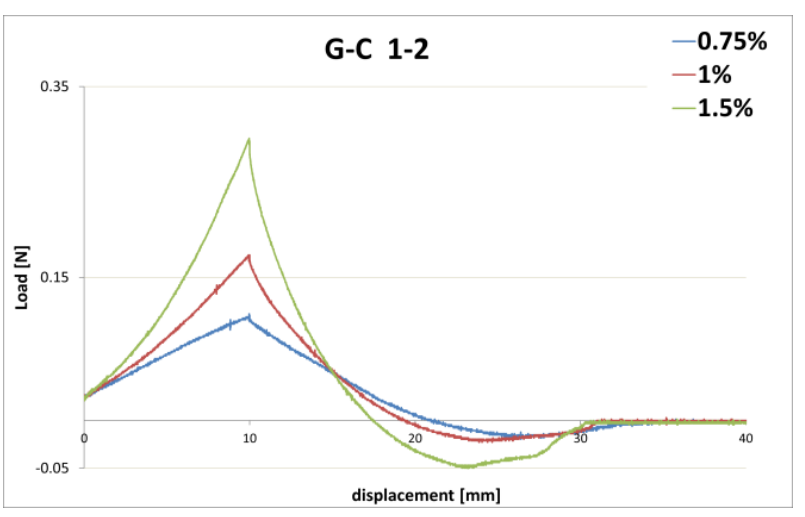

(a)

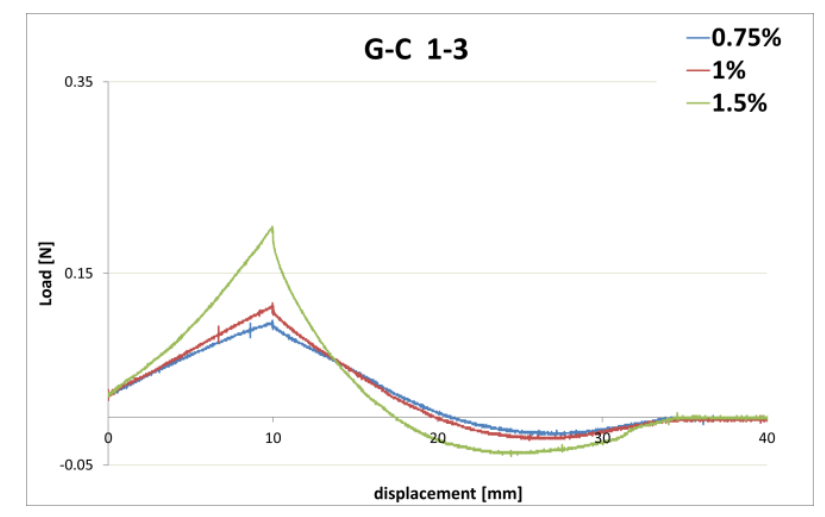

(b)

Figure 13. Texture curves obtained by an immersion/de-immersion test performed on the samples prepared with increasing polysaccharide total amounts $(0.75 \%, 1 \%$, and $1.5 \% w / w)$ at different $\mathrm{G}-\mathrm{C}$ ratios: 1:2 (a) and 1:3 (b).

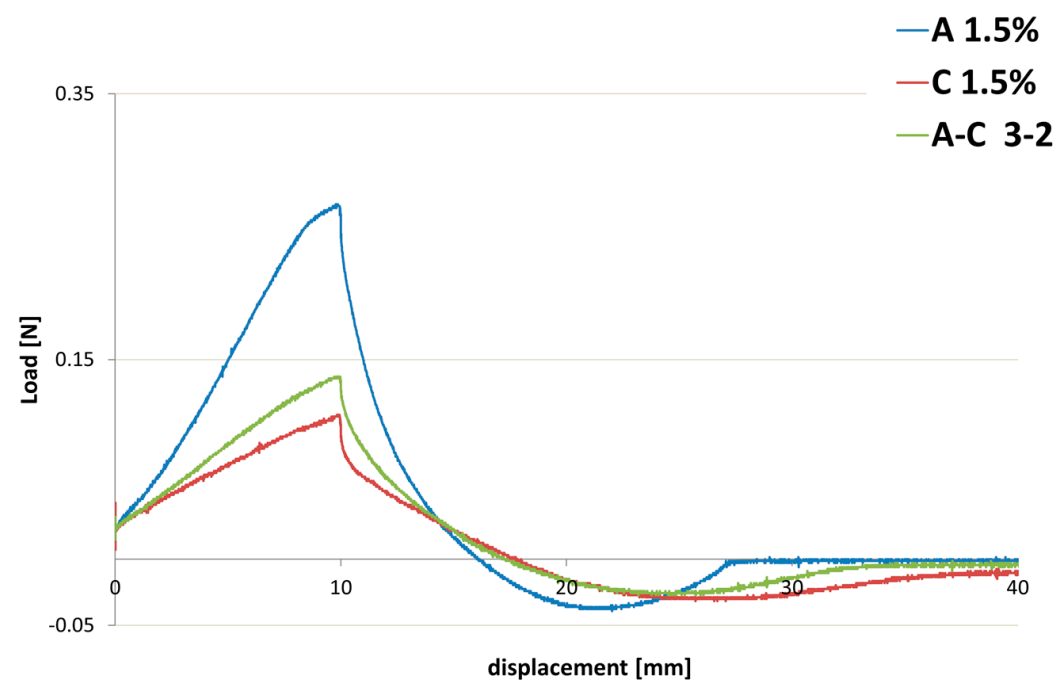

Figure 14. Texture curves obtained by an immersion/de-immersion test performed on the samples prepared with $\mathrm{A}, \mathrm{C}$, and the $\mathrm{A}-\mathrm{C}$ association (3:2) at the same total polymer amounts $(1.5 \% \mathrm{w} / \mathrm{w})$.



Figure 15. Texture curves obtained by an immersion/de-immersion test performed on the samples prepared with A-C association (3:2) with increasing total polymer amounts $(1.5 \%, 1.75 \%$, and $2 \% w / w)$. 


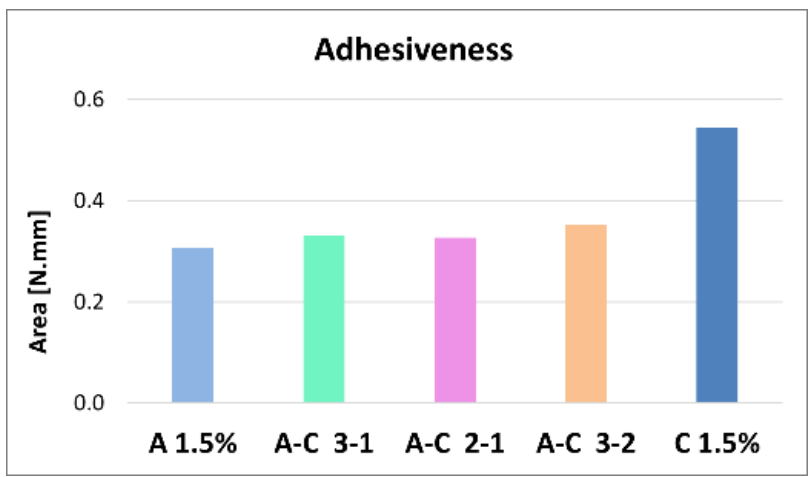

(a)

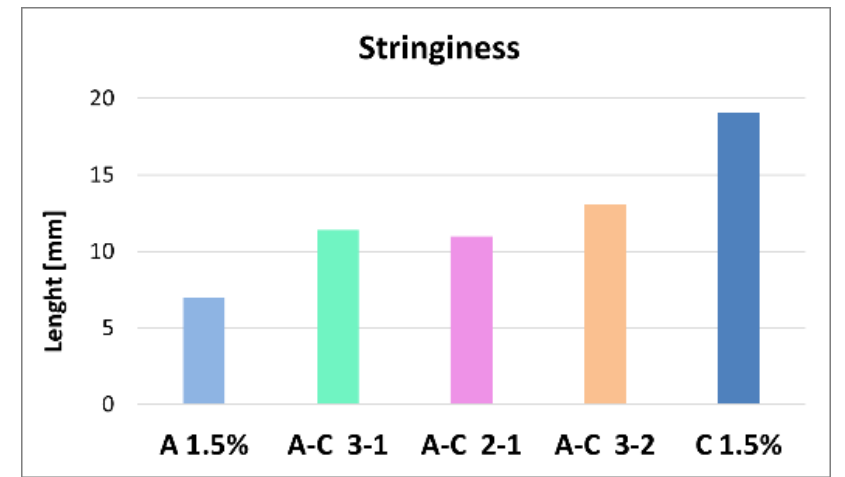

(b)

Figure 16. Textural parameters of adhesiveness (a) and stringiness (b) measured by an immersion/de-immersion test for the samples prepared with $\mathrm{A}-\mathrm{C}$ associations at different ratios $(1: 0,3: 1,2: 1,3: 2,0: 1)$ at $1.5 \%$ w/w of the total polymer amount.

\subsection{Selection of a Blend Suitable for Mucosal Application: Comparison with a Market Benchmark}

The data obtained through the physical-mechanical characterization of the polysaccharide associations were useful for obtaining different textures and selecting the combinations that were most suitable for the formulation of a mucoadhesive gel. A formulation that is intended to be applied on the oral mucosa must have an adequate firmness to allow correct extrusion and easy application. Moreover, it must exhibit high adhesive and cohesive properties to adhere to the application site and not be removed by mechanical movements. The results obtained for the ternary gel systems were compared with those obtained by measuring the texture properties of a benchmark (indicated as Ref.) proposed in the market for mucosal application (Table 1).

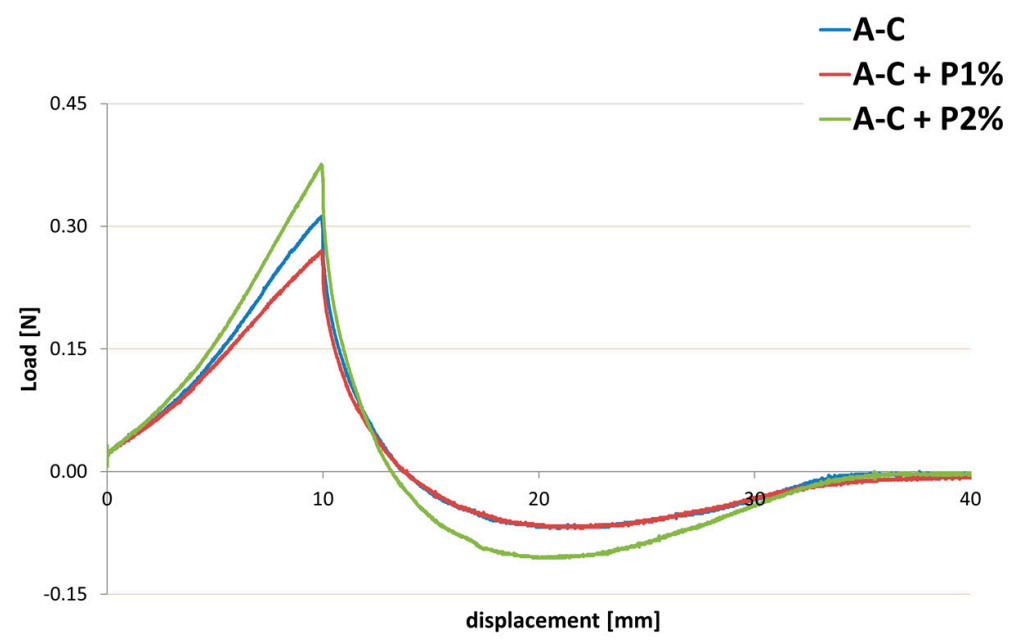

Figure 17. Texture profile of the samples prepared with ternary associations of A $(1.25 \% w / w)$, $\mathrm{C}(1 \% w / w)$, and $\mathrm{P}(0 \%, 1 \%$, and $2 \% w / w)$.

Table 1. Numerical values of the textural parameters measured by an immersion/de-immersion test for the samples prepared with ternary associations of $\mathrm{A}(1.25 \% w / w), \mathrm{C}(1 \% w / w)$, and $\mathrm{P}(0 \%, 1 \%$, and $2 \% w / w)$, and of the reference product (Ref.).

\begin{tabular}{cccccc}
\hline Samples & $\begin{array}{c}\text { Firmness } \\
{[\mathbf{N}]}\end{array}$ & $\begin{array}{c}\text { Consistency } \\
{[\mathbf{N} \cdot \mathbf{m m}]}\end{array}$ & $\begin{array}{c}\text { Cohesiveness } \\
{[\mathbf{N}]}\end{array}$ & $\begin{array}{c}\text { Adhesiveness } \\
{[\mathbf{N} \cdot \mathbf{m m}]}\end{array}$ & $\begin{array}{c}\text { Stringiness } \\
{[\mathbf{m m}]}\end{array}$ \\
\hline A-C & 0.31 & 1.84 & 0.07 & 0.98 & 13.43 \\
A-C + P1\% & 0.27 & 1.66 & 0.07 & 1.03 & 16.77 \\
A-C + P2\% & 0.38 & 2.09 & 0.11 & 1.47 & 15.12 \\
Ref. & 0.37 & 2.21 & 0.11 & 1.65 & 18.52 \\
\hline
\end{tabular}


The mixture with $\mathrm{P}$ at $2 \% w / w$ allowed higher values of adhesiveness and showed almost the same values of firmness, consistency, and cohesiveness as the reference product (Ref.) (Figure 18).



Figure 18. Comparison between the texture profile of the sample prepared with the ternary association of $\mathrm{A}(1.25 \% w / w), \mathrm{C}(1 \% w / w)$, and $\mathrm{P}(2 \% w / w)$, and of the reference product (Ref.).

The results from the controlled shear rate tests showed that the $\mathrm{A}-\mathrm{C}$ mixture with $\mathrm{P}$ at $2 \% w / w$ and the reference product had similar zero-shear viscosity $\left(\eta_{0}\right)$ values, calculated using the Carreau-Yasuda model (Figure 19).



Figure 19. Comparison between the zero-shear viscosity $\left(\eta_{0}\right)$ values, calculated via the CarreauYasuda model, for the sample prepared with ternary associations of A $(1.25 \% w / w), \mathrm{C}(1 \% w / w)$, and $\mathrm{P}(2 \% w / w)$, and for the reference product (Ref.).

The viscoelastic properties of the gel formulated with the $\mathrm{A}-\mathrm{C}$ mixture and $\mathrm{P}$ at $2 \%$ $w / w$ were compared with those of the reference product (Ref.). Both the samples showed a weak gel rheological pattern (Figure 20a). The moduli settled between the second and the third decades and, although the elastic $G^{\prime}$ was higher than the viscous $G^{\prime \prime}$ throughout the whole frequency range investigated, they showed a slight dependence on the frequency applied. The mixture with $\mathrm{P}$ at $2 \% w / w$ showed a more structured and elastic component than the reference gel, as shown by the lower tan $\delta$ (Figure 20b). 


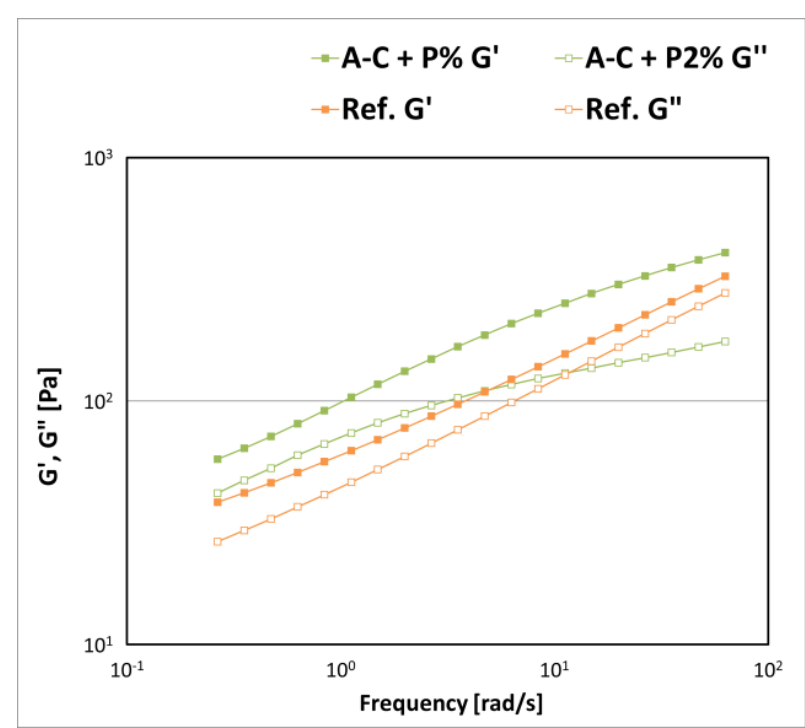

(a)

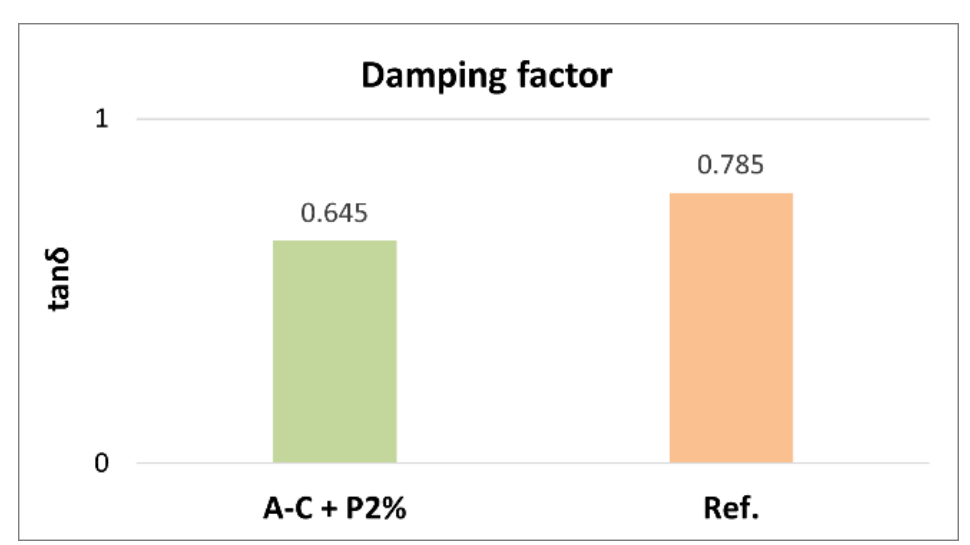

(b)

Figure 20. Storage $\left(G^{\prime}\right)$ and loss $\left(G^{\prime \prime}\right)$ moduli trend as a function of the frequency (a) and damping factor tan $\delta$ taken at $0.5 \mathrm{~Hz}$ (b) measured for the sample prepared with ternary associations of $\mathrm{A}(1.25 \% w / w), \mathrm{C}(1 \% w / w)$, and $\mathrm{P}(2 \% w / w)$ compared with the reference product (Ref.).

\section{Conclusions}

The intense pressure from the media and consumers for sustainability and eco-friendly choices have forced the cosmetic industries to focus on formula ingredients. In particular, many synthetic polymers are facing possible restrictions because of their non-biodegradable nature and many environmental issues. Polysaccharide associations may be viable alternatives for use in cosmetics as stabilizers and rheological modifiers. Rheological and texture analyses have proved to be powerful tools for outlining the physico-mechanical properties of different raw materials and to overcome the trial and error approach to formulation design. In this work, binary and ternary combinations of polysaccharides were evaluated using these instrumental techniques. The results obtained confirmed that natural raw materials with different applicative properties can be used in associations in appropriate ratios and concentrations to obtain a wide range of texture and sensorial properties. When iota-carrageenan $(\mathrm{G})$ was combined with carob gum $(\mathrm{C})$ at low total polymer amounts $(0.75-1 \% w / w)$, viscous fluid systems were formed, whereas at higher concentrations, the dispersions became bouncy and non-homogenous. The association of Sclerotium gum (A) with carob gum (C) with the addition of pectin (P) allowed modulation of the elastic properties, related to the physical stability and film-forming ability, and the viscous properties, related to the spreadability and the ease of application, conferred by the single raw materials. In particular, the ternary associations with $\mathrm{A}(1.25 \% w / w)$, $\mathrm{C}(1 \% w / w)$, and $\mathrm{P}(2 \% w / w)$ were characterized by the highest viscosity and adhesive properties, which were close to those of the reference product, which is intended for application on the oral mucosa. Textural and rheological analyses turned out to be powerful and complementary instruments for the characterization of the applicative properties of polymeric mixtures and represent useful tools for manufacturers to achieve their proposed objectives with a time- and money-saving approach. Moreover, the objective data on the spreading and the adhesive properties obtained with this instrumental approach represent the starting point for subsequent in vitro and in vivo efficacy tests and can facilitate the correct choice of raw materials, early identifying any critical issues that may be found during the product production phase. 
Supplementary Materials: The following are available online at https: / www.mdpi.com/article/ 10.3390 / cosmetics8030062/s1. Table S1: Samples submitted to the rheological and texture analyses, and the concentrations of the polymers used alone or in association. Figure S1: Pictures of the water dispersion of $G(a), C$ 's water dispersion (b), and G-C's water dispersion at a ratio of 1:3 (c) at a concentration of $1.5 \% w / w$. Figure S2: Frequency sweep tests repeated three times for the samples containing the polysaccharidic associations $\mathrm{G}-\mathrm{C}(\mathrm{a}), \mathrm{A}-\mathrm{C}(\mathrm{b})$, and A-C-P (c). Figure S3: Curve obtained by an immersion/de-immersion test, performed with a Texture Analyzer, and the definitions of the calculated parameters.

Author Contributions: Conceptualization, A.S. and G.T.; investigation, A.C. and G.T.; resources, L.B.; project administration A.C.; formal analyses, G.T.; writing-original draft preparation, G.T.; writing-review and editing, A.C.; supervision, G.B. and S.F. All authors have read and agreed to the published version of the manuscript.

Funding: This research received no external funding.

Institutional Review Board Statement: Not applicable.

Informed Consent Statement: Not applicable.

Data Availability Statement: Not applicable.

Acknowledgments: The authors would like to acknowledge Giulia Galizia from Unired Srl. for writing assistance and language editing.

Conflicts of Interest: The authors declare no conflict of interest.

\section{References}

1. Schneiders, B.; Anklin, F. The social impact of a cosmetics company. In Sustainability: How the Cosmetics Industry Is Greening Up; Sahota, A., Ed.; John Wiley \& Sons, Ltd.: London, UK, 2014; pp. 47-68.

2. Semenzato, A.; Costantini, A.; Baratto, G. Green Polymers in Personal Care Products: Rheological Properties of Tamarind Seed Polysaccharide. Cosmetics 2015, 2, 1-10. [CrossRef]

3. Lapasin, R.; Pricl, S. Rheology of Industrial Polysaccarides, Theory and Application; Blackie Academic \& Professional: London, UK, 1995.

4. Liao, S.H.; Hsieh, C.L.; Huang, S.P. Mining product maps for new product development. Expert Syst. Appl. 2008, 34, 50-62. [CrossRef]

5. Tafuro, G.; Costantini, A.; Baratto, G.; Busata, L.; Semenzato, A. Rheological and Textural Characterization of Acrylic Polymer Water Dispersions for Cosmetic Use. Ind. Eng. Chem. Res. 2019, 58, 23549-23558. [CrossRef]

6. Gilbert, L.; Picard, C.; Savary, G.; Grisel, M. Rheological and textural characterization of cosmetic emulsions containing natural and synthetic polymers: Relationships between both data. Colloids Surf. A Physiochem. Eng. Asp. 2013, 421, 150-163. [CrossRef]

7. Semenzato, A.; Costantini, A.; Meloni, M.; Maramaldi, G.; Meneghin, M.; Baratto, G. Formulating O/W Emulsions with Plant-Based Actives: A Stability Challenge for an Effective Product. Cosmetics 2018, 5, 59. [CrossRef]

8. Tadros, T. Application of rheology for assessment and prediction of the long-term physical stability of emulsions. Adv. Colloid Interface Sci. 2004, 108-109, 227-258. [CrossRef] [PubMed]

9. Peng, F.; He, S.; Yi, H.; Li, Q.; Xu, W.; Wang, R.; Ma, Y. Physical, textural, and rheological properties of whipped cream affected by milk fat globule membrane protein. Int. J. Food Prop. 2018, 21, 1190-1202. [CrossRef]

10. Tai, A.; Bianchini, R.; Jachowicz, J. Texture analysis of cosmetic/pharmaceutical raw materials and formulations. Int. J. Cosmet. Sci. 2014, 36, 291-304. [CrossRef] [PubMed]

11. Gilbert, L.; Savary, G.; Grisel, M.; Picard, C. Predicting sensory texture properties of cosmetic emulsions by physical measurements. Chemometr. Intell. Lab. 2013, 124, 21-31. [CrossRef]

12. Tafuro, G.; Costantini, A.; Baratto, G.; Francescato, F.; Semenzato, A. Evaluating natural alternatives to synthetic acrylic polymers: Rheological and texture analyses of polymeric water dispersions. ACS Omega 2020, 5, 15280-15289. [CrossRef]

13. Amasya, G.; Karavana, S.Y.; Sen, T.; Baloglu, E.; Tarimci, N. Bioadhesive and mechanical properties of triamcinolone acetonide buccal gels. Turk. J. Pharm. Sci. 2012, 9, 1-12.

14. Perioli, L.; Pagano, C.; Mazzitelli, S.; Rossi, C.; Nastruzzi, C. Rheological and functional characterization of new antiinflammatory delivery systems designed for buccal administration. Int. J. Pharm. 2008, 356, 19-28. [CrossRef]

15. Sudhakar, Y.; Kuotsu, K.; Bandyopadhyay, A.K. Buccal bioadhesive drug delivery-A promising option for orally less efficient drugs. J. Control. Release 2006, 114, 15-40. [CrossRef]

16. Lapasin, R.; Abrami, M.; Grassi, M.; Sebenik, U. Rheology of laponite-scleroglucan hydrogels. Carbohydr. Polym. 2017, 168, 290-300. [CrossRef]

17. Blakemore, W.R.; Harpell, A.R. Carrageenan. In Food Stabilizers, Thickeners and Gelling Agents; Imeson, A., Ed.; Wiley-Blackwell: Oxford, UK, 2010; pp. 73-94.

18. Dionisio, M.; Grenha, A. Locus bean gum: Exploring its potential for biopharmaceutical applications. J. Pharm. Bioallied Sci. 2012, 4, 75-85. 
19. Prajapati, V.D.; Jani, G.K.; Moradiya, N.G.; Randeria, N.P.; Nagar, B.J.; Naikwadi, N.N.; Variya, B.C. Galactomannan: A versatile biodegradable seed polysaccharide. Int. J. Biol. Macromol. 2013, 60, 83-92. [CrossRef]

20. Martau, G.A.; Mihai, M.; Vodnar, D.C. The Use of Chitosan, Alginate, and Pectin in the Biomedical and Food SectorBiocompatibility, Bioadhesiveness, and Biodegradability. Polymers 2019, 11, 1837. [CrossRef]

21. Yasuda, K.; Armstrong, R.C.; Cohen, R.E. Shear flow properties of concentrated solutions of linear and star branched polystyrenes. Rheol. Acta 1981, 20, 163-178. [CrossRef]

22. Fernandes, P.B.; Gonçalves, M.P.; Doublier, J.L. Influence of locust bean gum on the rheological properties of kappa-carrageenan systems in the vicinity of the gel point. Carbohydr. Polym. 1993, 22, 99-106. [CrossRef]

23. Haddarah, A.; Bassal, A.; Ismail, A.; Gaiani, C.; Ioannou, I.; Charbonnel, C.; Hamieh, T.; Ghoul, M. The structural characteristics and rheological properties of Lebanese locust bean gum. J. Food Eng. 2014, 120, 204-214. [CrossRef]

24. Yanga, D.; Gaoa, S.; Yang, H. Effects of sucrose addition on the rheology and structure of iota-carrageenan. Food Hydrocoll. 2020, 99, 105317. [CrossRef]

25. Moresi, M.; Lo Presti, S.; Mancini, M. Rheology of scleroglucan dispersions. J. Food Eng. 2001, 50, 235-245. [CrossRef]

26. Lopes da Silva, J.A.; Goncalves, M.P.; Rao, M.A. Rheological properties of high-methoxyl pectin and locust bean gum solutions in steady shear. J. Food Sci. 1992, 57, 443-448. [CrossRef]

27. Thrimawithana, T.R.; Younga, S.; Dunstanb, D.E.; Alanya, R.G. Texture and rheological characterization of kappa and iota carrageenan in the presence of counter ions. Carbohydr. Polym. 2010, 82, 69-77. [CrossRef]

28. Wang, F.; Wang, Y.J.; Sun, Z. Conformational role of xanthan in its interaction with locust bean gum. J. Food Sci. 2006, 67, 2609-2614. [CrossRef]

29. Craig, D.Q.M.; Kee, A.; Tamburic, S.; Barnes, D. An investigation into the temperature dependence of the rheological synergy between xanthan gum and locust bean gum mixtures. J. Biomater. Sci. 1997, 8, 377-389. [CrossRef] 